\title{
Do Migrant Children Face Greater Health Hazards in Slum Settlements? Evidence from Nairobi, Kenya
}

\author{
Philippe Bocquier, Donatien Beguy, Eliya M. Zulu, Kanyiva
}

Muindi, Adama Konseiga, and Yazoumé Yé

\begin{abstract}
Between $60 \%$ and $70 \%$ of Nairobi City's population live in congested informal settlements, commonly referred to as slums, without proper access to sanitation, clean water, health care and other social services. Children in such areas are exposed to disproportionately high health hazards. This paper examines the impact of mother and child migration on the survival of more than 10,000 children in two of Nairobi's informal settlements-Korogocho and Viwandani-between July 2003 and June 2007, using a two-stage semi-parametric proportional hazards (Cox) model that controls for attrition and various factors that affect child survival. Results show that the slum-born have higher mortality than non-slum-born, an indication that delivery in the slums has long-term health consequences for children. Children born in the slums to women who were pregnant at the time of migration have the highest risk of dying. Given the high degree of circular migration, factors predisposing children born in the slums to recent migrant mothers to higher mortality should be better understood and addressed.
\end{abstract}

KEYWORDS Child mortality, Migration, Attrition, Two-stage Cox model, Informal settlements, Nairobi, Kenya

\section{INTRODUCTION}

The failure of urban economies to generate enough jobs and of local authorities to provide adequate housing, basic amenities, and other social services for the rapidly growing urban population have forced many poor urbanites to live in slum settlements because they cannot afford rent elsewhere. ${ }^{*}$ According to estimates by UN-Habitat, about $72 \%$ of all urban residents in sub-Saharan Africa are estimated to live in slum settlements since they lack the basic amenities associated with planned urban residence. ${ }^{1}$ Slums are sanctuaries for poor health because they are characterized by poor access to clean water, proper sanitation, garbage disposal and

\footnotetext{
*Many people choose also to live in the relatively cheap squatter settlements in order to accumulate savings for various investments in their home communities while acquiring the city experience that prepares them for a more permanent formal urban job.
}

Bocquier is with the Department of Demography and Population Studies, School of Social Sciences, University of the Witwatersrand, Johannesburg, Gauteng, South Africa; Beguy, Zulu, Muindi, and Yé are with the African Population and Health Research Center, Nairobi, Kenya; Zulu is with the African Institute for Development Policy (AFIDEP), P.O. Box 14688-00800, Westlands, Nairobi, Kenya; Konseiga is with the Institut IDEA International, Québec, QC, Canada; Yé is with the ICF Macro, 11785 Beltsville Drive, Suite 300, Calverton, MD 20705, USA.

Correspondence: Philippe Bocquier, PhD, Department of Demography and Population Studies, School of Social Sciences, University of the Witwatersrand, Johannesburg, Gauteng, South Africa. (E-mail: philippe.bocquier@gmail.com) 
drainage systems, overcrowding, poor housing conditions, and excessive environmental and air pollution. In fact, the growth of slums and the associated poor health outcomes in these settlements have been touted as the primary reason for the decline in the extent of advantage that urban areas have traditionally had over rural areas in various health outcomes in sub-Saharan Africa. ${ }^{2}$ Urban areas retain a health advantage at the aggregated level, but this advantage is not universal in Africa and is essentially resulting from the positive effect of individual and household characteristics rather than the sheer urban environment. ${ }^{3,4}$ Slum dwellers generally exhibit higher levels of morbidity, indulgence in risky sexual behaviors and drug abuse, lower utilization of health services, and higher mortality than other population subgroups, including rural residents. $^{5-10}$ The biggest inequities in health outcomes between slum and non-slum populations are observed among children. ${ }^{5}$ For instance, data from the slums of Nairobi show that children living in slum settlements are considerably more likely to get sick from infectious diseases, less likely to use medical services, and more likely to die than other major sub-populations, including rural residents. ${ }^{5,11}$ For instance, while infant mortality and child mortality rates for rural areas were 74 and 109 in 1998 according to DHS data, ${ }^{5,12}$ the equivalent rates for slum settlements were 91 and 151 , respectively, in 2000 according to the NCSS survey. ${ }^{5}$

Health indicators for slum dwellers are likely to shape national health indicators and the capacity of countries to achieve the health-related millennium development goals. Of particular interest to the study of Nairobi slums is the effect of migration of the mother and the child, as migration can have a selective effect on health. Migration cannot be discarded as a minor issue when the majority of the population are migrants. The proportion of Nairobi City-born residents does not exceed $20 \%$ for men and women of varying age groups, and half of the migrant residents came to Nairobi between 17 and 23 years old. ${ }^{13}$ Indeed, the majority of the residents aged 12 years and above in the two slum settlements studied in this paper $170 \%$ in Korogocho and $91 \%$ in Viwandani) were born in rural areas. ${ }^{14}$ In this study, we contribute to the understanding of the effect of migration ${ }^{14}$ and other determinants on child health by using longitudinal data collected from two slum settlements in Nairobi. A recent study comparing survival chances for children born in the same slum settlements between 2003 and 2006 by the mother's migration status showed that children born to recent migrants are 1.7 times more likely to die than those born to non-recent migrants. ${ }^{15}$ By restricting the analysis to children who were born in the slums, the study examined a very important dimension of the effect of migration on health outcomes-that even when children are born in and exposed to the same environment, the mother's migration status makes a difference. However, it is also important to understand the differences in child survival between children who have spent their entire lives in the slums, versus those who were born in other settings but migrated into the slum environment. In the present study, we examine the impact of the mother's duration of residence on the survival chances of all under-five children who were resident in the slum settlements for more than 4 months between 2003 and 2007.

\section{METHODS}

\section{Study Design and Analysis}

Our population of interest is children who were born between January 1, 2003 and December 31, 2007 and who lived in the slums before their 5th birthday during this 5 -year period. The children born in the slums are observed from birth. For the 
children born out of the slums, we use a 4-month minimum duration of residence threshold. In that way, the analytical definition does not depend on the operational migration definition in the Nairobi Urban Health and Demographic Surveillance System (NUHDSS), since the threshold period for in- and out-migration in the NUHDSS was 3 months between 2003 and 2006 and changed at the beginning of 2007 to 4 months.

In principle, we could have taken into account the children who were born before 2003 in the analysis. These would have been left-censored from January 1, 2003. However, the place of birth and the migration status of children born before 2003 were not collected. These children are thus excluded from the analysis.

Analysis of migration patterns ${ }^{16}$ shows some inconsistencies in the data on the first two and the last two quarters of our observation period. Inconsistent migration trends were observed before July 2003 and reflecting unstable data collection procedures. Migration trends were also found inconsistent after July 2007 but that reflects the "hanging cases," i.e., when some people who are reported to have made an internal movement are only found in any other location in the demographic surveillance area (DSA) several rounds of visit later. To avoid these migration biases affecting our analyses, we excluded data collected during these four quarters. Therefore, the outcome of interest was the death of children who resided in the slums after July 1, 2003: The 10,445 children at risk lived 13,114 person-years and 465 of them died by June 31, 2007. Because of the period restriction, we will be able to measure mortality until 48 months (4 years) and not 60 months (5 years).

We used a semi-parametric proportional hazards (Cox) model to assess the effect of the mother and child's migration on childhood survival rates, after controlling for the effect of a number of determinants. For each child, the observation time was age, starting at birth (if born in the study area) or at age reached after 4 months of inmigration in the slums (if born outside the study area) between July 2003 and June 2007. The observation ending either at their 4th birthday, at the occurrence of the event of interest (death) or dates of censoring due to refusal, loss to follow-up, emigration, or end of the follow-up when the observation time was truncated for the children who were still alive on June 31,2007. We allowed gaps in the observation time, meaning that children could out-migrate and return to the slums.

We used a number of demographic and socioeconomic factors known to affect child survival as control variables. We have three types of control variables: (1) those directly related to the child (sex, migrant status), (2) those related to the mother (age, migrant status, ethnicity, and level of education), including her survival status as a timevarying covariate, i.e., a covariate that changes value from the time of occurrence of the change, (3) those related to the household economic status for the household where the child lives at any given time (access to tap water; access to own toilet; floor finish; roof finish; access to Kenya Power and Lighting Company (KPLC) electricity; ownership of dwelling unit; ownership of phone, radio, and TV), and (4) those related to the context (slum area, trimester introduced as a time-varying continuous variable to measure the overall trend over the study period). Unfortunately, classic determinants of child mortality such as birth interval and birth order were not available for all children and therefore could not be included in the model.

The focus of this paper is on the variable that combines place of birth of the child (in or out of the slums) and duration of residence of the mother in the slums. As explained earlier, this information was not available for children born prior to 2003. Children were classified according to the duration of residence of their mother in the slums at their birth in four categories. The children born before their mothers 
migrated to the slums form the first category, which is the reference category in the regression analysis. The second category is constituted of the children born within 8 months of the mother's migration, i.e., children who have most likely been conceived before their mothers migrated to the slums. Because their mothers migrated while pregnant, the migration might actually be motivated by the pregnancy. The migration might also have represented a stress for the migrant mother, with possible long-term consequences on the child survival. The children born within 9 to 19 months following mother's migration constitute a third category. These children were conceived within 1 year of mother's migration to the slums, at a time when their mother might have been particularly vulnerable socially and economically. The fourth category is formed by the children born 20 months or more after the mother's migration (i.e., conception most likely to have occurred after 1 year of mother's migration in the slums). Children born of non-migrant mothers are included in this last category, called the long-term migrants for convenience."

One out of five babies born after their mother's migration were actually delivered out of the slums, the mother thus spending some weeks or months out of the slums, while still considered in the HDSS system as residents because they spend less than 4 months out of the slums for delivery. Therefore, a child can either be born out of or in the slums whatever the above categories except the first (born before mother's migration in the slums). When born out of the slums, the child is included in the population at risk 4 months after his or her migration in the slums. This means that deaths occurring in the first 4 months following in-migration are not taken into account. Our mortality estimates are therefore conservative since we exclude deaths that could have been caused by conditions prevailing before inmigration. So we are comparing death rates of seven categories of children, as depicted in Table 1. Out-migration of the mother without the child is not controlled for in the present analysis. We assume that the mother and the child are living together over the exposure period.

\section{Migration in Longitudinal Analysis of Mortality}

One of the most critical issues that one should take note of and possibly control for in longitudinal analyses is attrition, especially in cases where those leaving the study area are predisposed to different risks of dying compared with the general population. Attrition is particularly important in the NUHDSS setting because of the nonpermanence of housing structures, unreliability of livelihood opportunities, and the consequent high levels of population mobility both within and outside the location. The two main sources of attrition in the NUHDSS are mainly out-migration and to a lesser extent loss to follow-up. Analysis of data of people who migrated to the slum settlements between 2003 and 2007 shows that the median duration of stay for the new migrants was 22 months for males and 26 months for females in Korogocho and 18 months for females and 22 months for males in Viwandani. ${ }^{14}$

The NUHDSS field team sometimes fails to observe some individuals and households because it is hard to find an eligible respondent at home. The most difficult cases of loss to follow-up are named "hanging cases," which are cases where the fieldworker confirms that the respondent has left the housing unit where he/she was

\footnotetext{
"It should be noted that most mothers who were in the study area when APHRC started running the NUHDSS were migrants. Only about $25 \%$ and $5 \%$ of the residents aged 12 years and above were born in Korogocho and Viwandani settlements, respectively.
} 


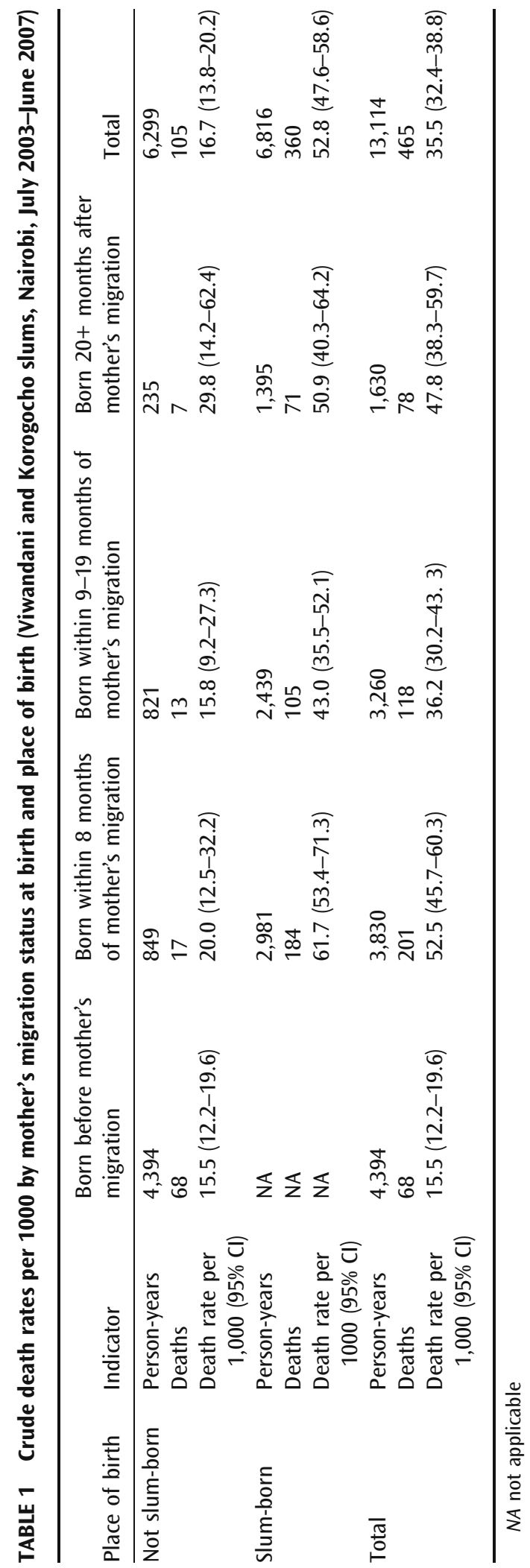


living during the last visit and is informed that the person has moved to another location within the study area. However, fieldworkers sometimes fail to trace the person in the new location for several rounds. These cases are called "hanging cases" because they are part of the health and demographic surveillance system (HDSS) since they have not died or out-migrated, but they are not found at any other DSA location either. Because the effect of hanging cases is the same as out-migration (in that no events or updates can be done regarding the person), out-migration and hanging cases are combined in one category to form the overall attrition. Out-migration is by far the most dominant source of attrition from the NUHDSS population. The NUHDSS data show that out of the 60,207 people (total population) who left the surveillance population between 2003 and 2007, out-migration accounted for 92\%, while hanging cases and deaths accounted for $5 \%$ and $3 \%$, respectively. ${ }^{17}$

Therefore, migration is a major source of population change in HDSS. The smaller the study area, the larger the migration is compared with other demographic phenomena. In Nairobi slums, the annual in-migration rate is $27.1 \%$ while the outmigration rate is $26.7 \%$. This results in a dramatic turn-over of the slum population. The rates are even higher for the children under 5 years, respectively, 36.9\% for inmigration and $31.4 \%$ for out-migration. ${ }^{16}$ It is imperative to understand the effect of such intense migration on health outcomes.

Other studies in Africa already showed that sending areas (mainly with prominently rural environment) experience an excess mortality due to people "returning home to die". ${ }^{18,19}$ It is expected, therefore, that receiving areas would experience the opposite in that mortality might be underestimated due to migrants returning to the sending areas "to die" when they get (or are deemed at risk of getting) sick. It is not quite clear whether this pattern could apply to children as well, considering that it is not them who make the decision to migrate but their parents. Yet our hypothesis is that when children are deemed at risk of getting sick, as they often would in a very deplorable environment that is conducive to the spread of infectious diseases, their mothers would rather out-migrate to their origin area or send their children to this area for better care. The mortality should therefore be underestimated in a context of high circular migration pattern in a poor health environment. As we do not have follow-up data on the return migrants in their origin area to support that (it might be that the health conditions are not better than in the slums), we use a modeling approach to verify this hypothesis, as explained in the next section.

\section{Two-Stage Equation Models to Control for Selection}

The semi-parametric proportional hazards (Cox) model used in this analysis makes the assumption that all covariates have a proportional effect on survival whatever the age. The relative risk associated with a given covariate $x$ is assumed to be the same on mortality rate $\lambda_{0}(t)$ at each age $t$ :

$$
\lambda_{x}(t \mid x)=\lambda_{0}(t) \exp ^{\mathrm{x} \beta} .
$$

However, because not all children are born in the slums, the non-slum-born effect can only be computed after the children have reached 4 months of age $(t=4)$, which is the minimum time to be considered a resident in the slums. To check the effect of this limitation, we compared regression results in Table 2 with data excluding the first 4 months for both slum-born and non-slum-born and found no difference in direction or significance of covariates, including slum-born effect.

All event history analyses make the explicit assumption of independence between censoring and event. When censoring is not independent from the event 


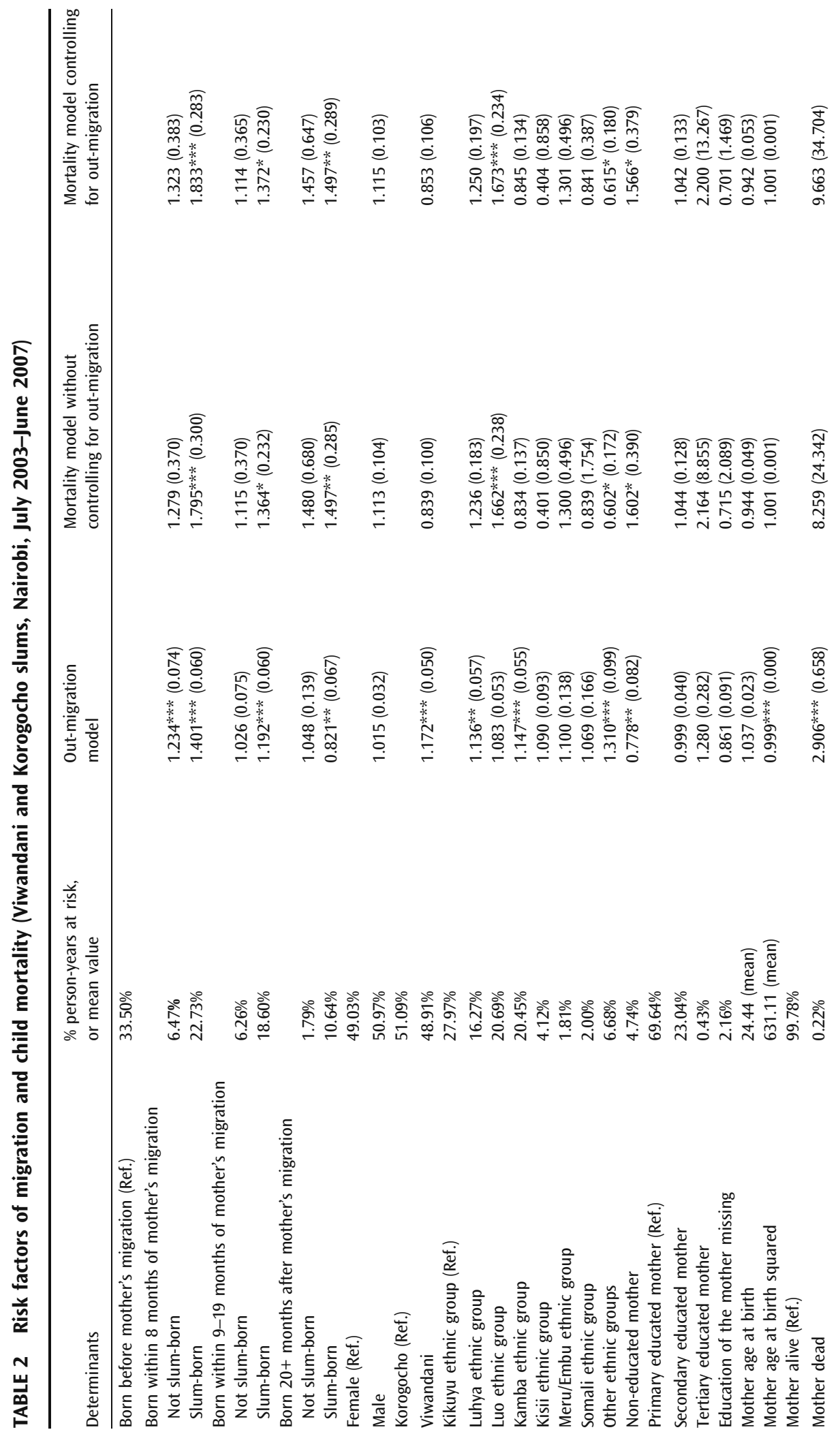




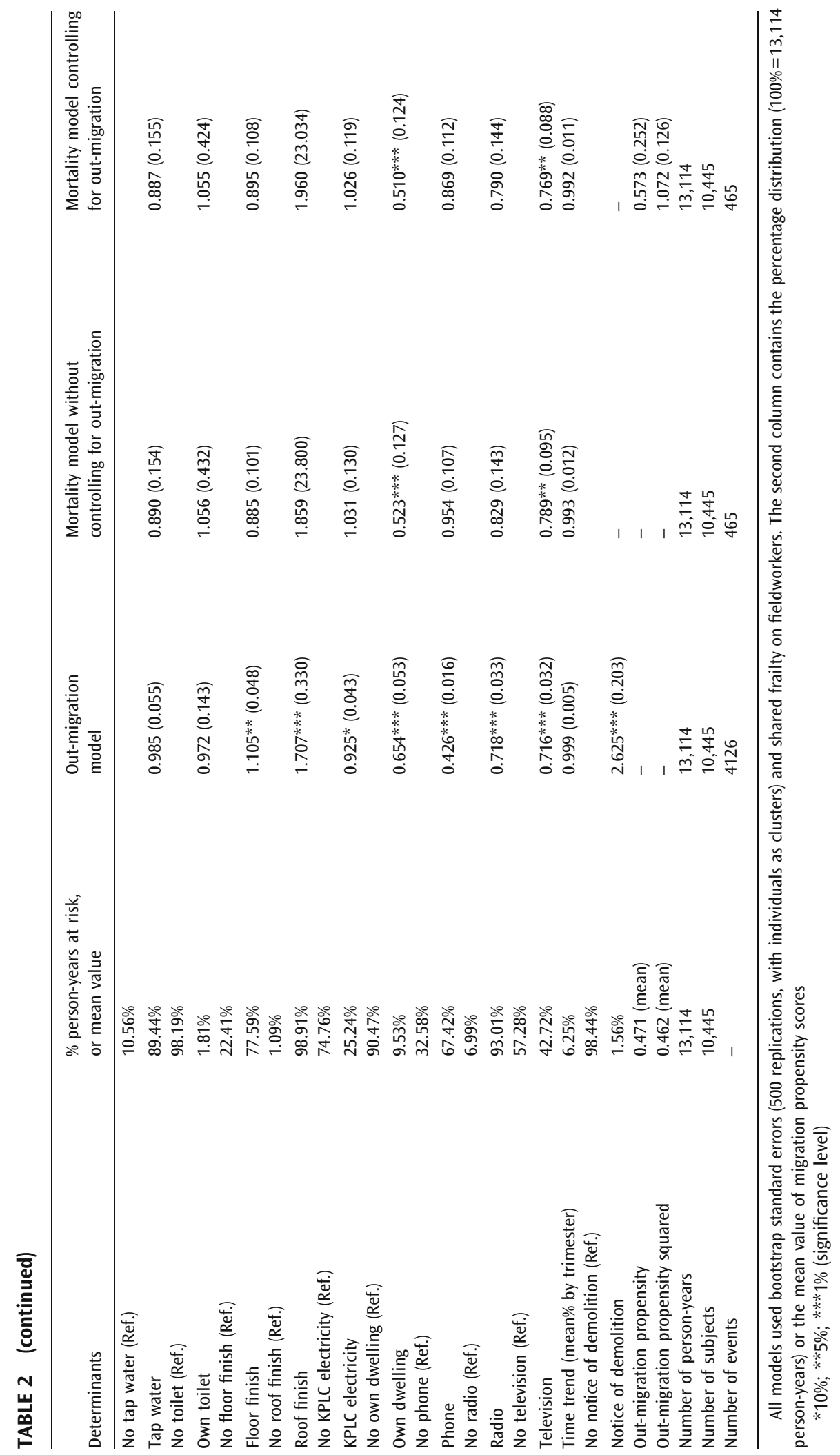


of interest (e.g., migration in relation to death) then the results suffer from potential bias. In this analysis, we control for non-independent censoring and the consequent selection bias, i.e. when the same determinants may cause attrition and mortality. We adapted to the context of longitudinal data the two-stage equation model that has originally been developed for the control of endogeneity in cross-sectional data. The attrition (out-migration) risk is modeled using available independent variables, including an instrumental variable, e.g., a variable that affects attrition but not mortality.

The selection (censoring by out-migration) equation takes the form:

$$
\lambda_{C \mid Z(t)}(t \mid z(t))=\lambda_{C 0}(t) \exp ^{z(t) \beta} .
$$

The main (mortality) equation takes the form:

$$
\lambda_{T \mid x(t)}(t \mid x(t))=\lambda_{T 0}(t) \exp ^{x(t) \beta+\Lambda_{-1}(t) \alpha},
$$

where:

$$
\Lambda_{-1}(t)=\sum{ }_{(j=1)}^{N} \lambda_{C \mid Z(t)}(t \mid z(t)) . I\left(C_{j} \leq t\right),
$$

is the cumulative hazard function computed at the observed informative censoring time $C$ only. It is interpreted as a propensity (and not a probability since the cumulative hazard can take value higher than 1) to have out-migrated of the population at risk by censoring time $t$. The cumulative hazard function is preferred to the inverse of the survival function because of its generalization to renewable event, as is out-migration. The squared propensity term can also be introduced in the model to test non-linear effect of attrition.

The vectors $Z$ and $X$ are the covariates respectively for the selection and main equations that verify $Z=X+V . V$ is a vector of instrumental covariates (variables that can explain the selection but not the event) typically related to data collection issues or to calendar effects that influenced the selection.

Taking the log of the main equation and rearranging gives:

$$
y(t)=\log \left[\frac{\lambda_{T \mid x(t)}(t \mid x(t))}{\lambda_{T 0}(t)}\right]=x(t) \beta+\Lambda_{-1}(t) \alpha
$$

The equation $y(t)$ is identified if $Z \neq X$, i.e. when the residuals of $y(t)$ are not correlated with instrumental variables $v(t)$ included in vector of covariates $z(t)=x(t)+v(t)$ used to compute the propensity $\Lambda_{-1}(t)$. Here we use as an instrumental variable $v(t)$, the notice of demolition of household structures under the KPLC electric lines (and to a lesser extent next to the Kenya Railway lines and Kenya Pipelines) that led to massive out-migration of part of the study population in 2004."

*KPLC issued a notice to all residents of Nairobi City whose houses were located below high voltage electricity lines to demolish their dwelling units within three months or face force eviction/demolition. This led to mass demolition of houses in the two slums and while some of the residents relocated to other dwelling units within the two slums, a lot of the people from the affected houses moved out of the slums. That is why 2004 has a markedly higher number of out-migrants than the other years. While the notice of demolition clearly led to a higher level of attrition, there is no reason to believe that the departure from the study population due to this fact affected survival probabilities of the children beyond the normal effect of out-migration. 


\section{RESULTS}

Crude death rates by migration categories are presented in Table 1 . These rates cannot be compared between slum-born and non slum-born as the first age-group (0-3 months) is not included in the computation for non-slum-born. For the same reason, Kaplan-Meier estimates cannot be computed for all categories of migrants and age groups. The Kaplan-Meier estimate of ${ }_{0} \mathrm{q}_{48}$ (under-4 mortality) for the slum-born is 108.4 per 1,000 (95\% CI: 96.2-122.0) but this cannot be computed for the non-slum-born. However, Nelson-Aalen estimates can be computed at least from 4 months of age. Figure 1 shows that children born before their mother's migration to the slums have the lowest mortality while those born within 8 months of their mother's migration have the highest mortality. Figure 2 shows some evidence that among the latter category, mortality is higher for children born in the slums although the difference is not significant. Mortality does not differ by place of birth in other categories (not shown). These mortality estimates, however disaggregated by migration status, cannot provide control for all possible confounders. For that, a regression framework as presented in the method section is more appropriate. Table 2 presents the results from the analysis with the following three models:

1. The attrition (out-migration) model: note the use of the demolition notice as an instrument (determinant of attrition but not of mortality).

2. The base mortality model with covariates but no control for attrition.

3. Mortality model controlling for attrition (using cumulative hazards computed from attrition model, and its squared value to check for non-linear effect) and other covariates.

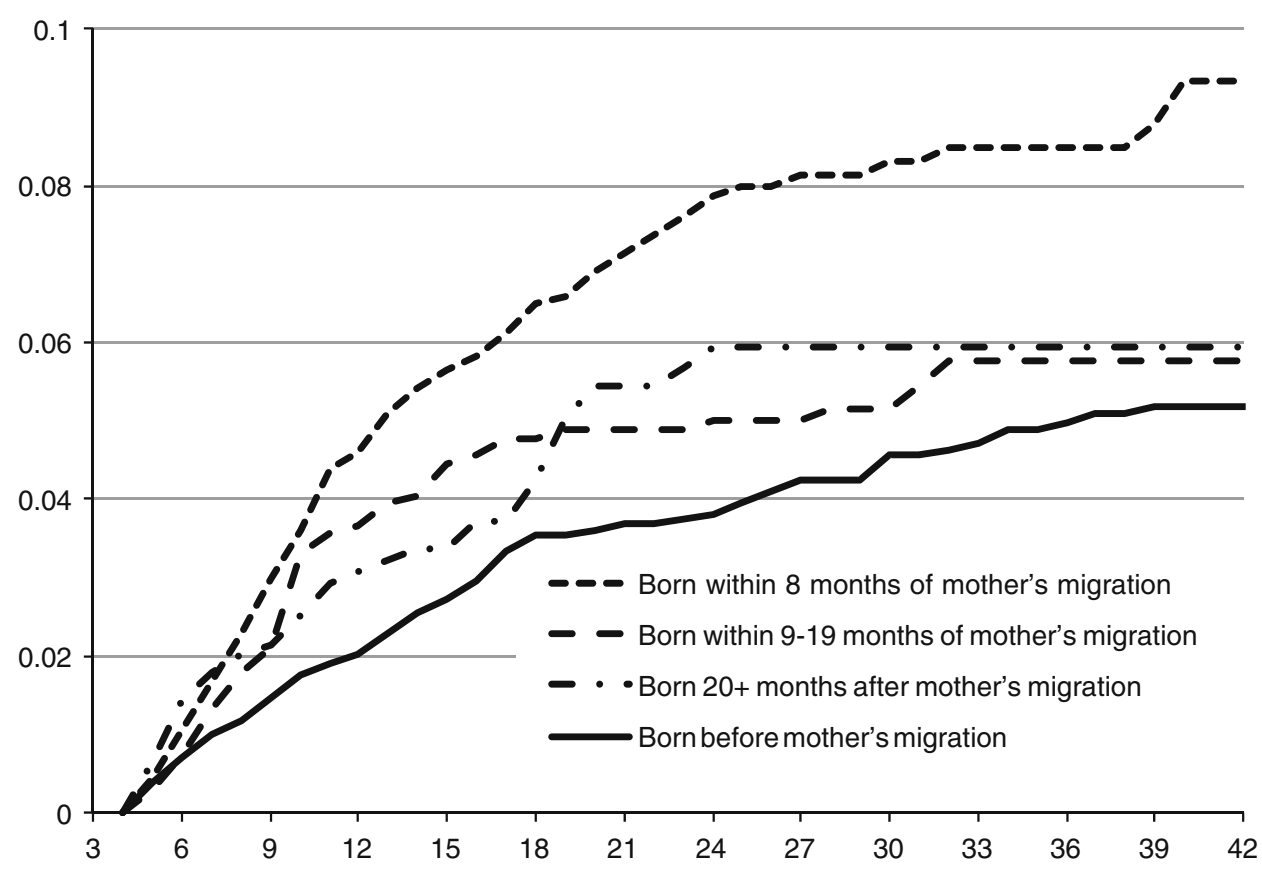

FIGURE 1. Nelson-Aalen mortality estimates from age 4 to 42 in months by mother's migration status at birth. 


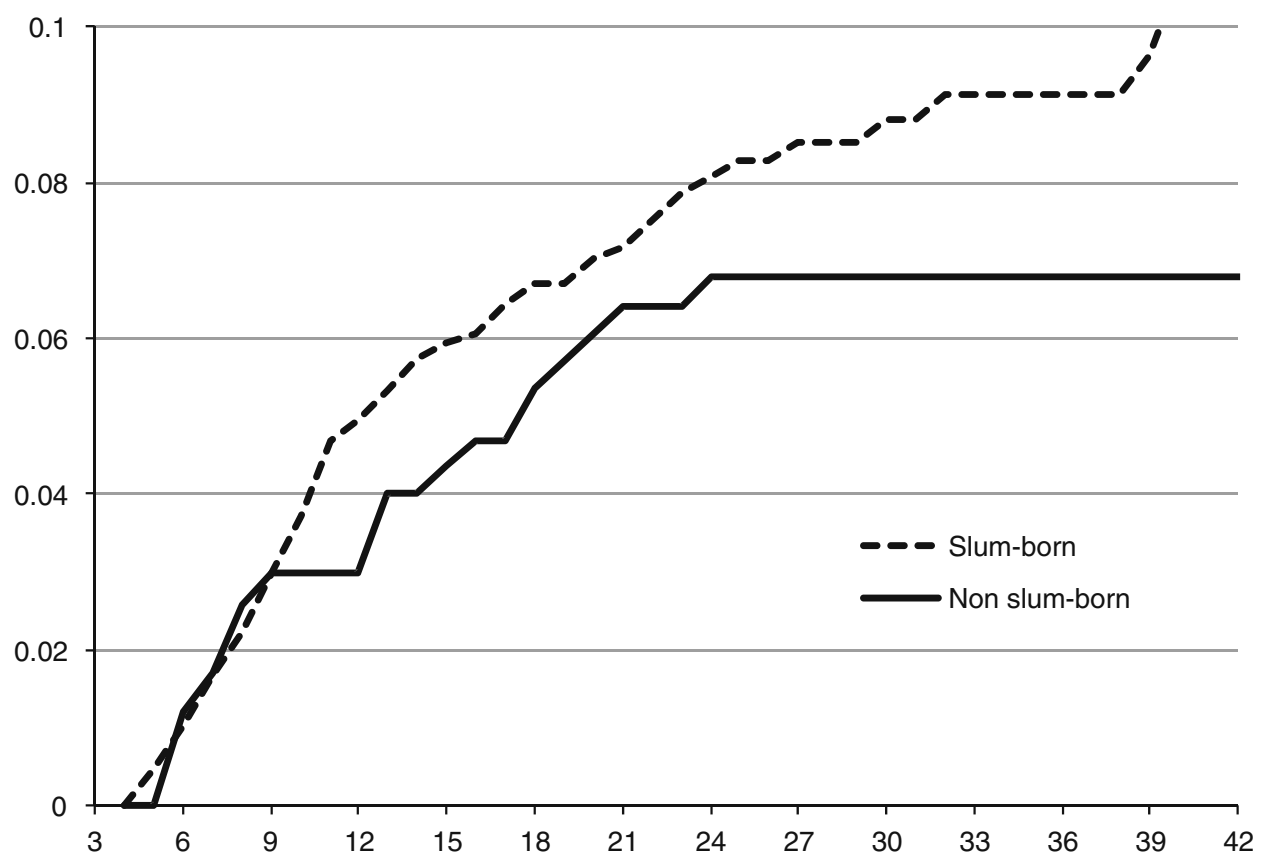

FIGURE 2. Nelson-Aalen mortality estimates from age 4 to 42 in months by place of birth of children born within 8 months of their mother's migration.

To note, all these models are controlling for age although this part of the model is not shown in Table 2. Following the Cox proportionality assumption detailed in the methods section, each covariate is assumed to have a proportional effect at all ages.

\section{Attrition Model}

Migration status has a significant effect on the likelihood of leaving the study population during the study period (attrition). Children born within 8 months of the mother's migration have a higher chance of out-migrating than other categories of mother's duration of residence, whether they are slum-born or not. Our hypothesis is that having a child shortly after migration in the slums represents a high stress for the mother, and the new mother is likely to go back home with the child or to send the child "home." The socio-demographic characteristics of the mother have mild effects on attrition while the household economic conditions have significant effects. Although mother's age effect is not significant, there is evidence of a non-linear effect whereby children born of older mothers have a lower chance to out-migrate. The minority of children whose mother has no formal education have a lower probability to out-migrate. In general, those with higher economic status (as measured by household possessions and amenities) are less likely to leave, suggesting that departure from the slums reflects failure to find livelihood opportunities and afford houses with relatively good amenities. Children living in households that either own the dwelling unit, a phone, a radio, or a TV, are significantly less likely to move out of the study area. The lower chance to out-migrate associated with no floor and roof finish reflects the rental cost: cheap rent gives less incentive to move out. There are also significant differences in the likelihood of attrition across ethnic groups, with higher chances of attrition among the Kamba, Luhya, and the smallest ethnic groups compared with the Kikuyu. The Kikuyus' original home area 
(Central Province) is close to Nairobi and the lower levels of attrition in this group may be suggestive of the fact that many of the Kikuyus living in the slums are actually long stayers and more likely to be doing well economically. The notice of demolition effect is strong and significant $(\mathrm{HR}=2.6 ; p<0.01)$ on attrition.

\section{Mortality Model}

As shown in Table 2, the mortality models differ marginally whether we control for out-migration or not. The attrition effect is not significant but in the expected direction (HR: 0.6), confirming that out-migration may be endogenous to the mortality of the children. Censoring by out-migration may not seem to be independent from the death event and may therefore be a source of bias in estimating mortality. This result suggests that mortality rates in the slums would be higher if those who left had stayed in the population. In the following section, we comment only on the results of the mortality model controlling for out-migration propensity.

Mortality among children born in the slums is generally higher than that of nonslum-born children, although the joint equality test of slum-born against non-slum-born is not significant. Those born in the slums within 8 months of the mother's migration have the highest probability to die $(\mathrm{HR}=1.8 ; p<0.01)$, even when compared with the children born in the slums 9-19 months after the mother's migration (equality test significant at $p<0.05$ ). To note, the mortality of children to long-term migrant mothers does not differ whether they are born in the slums or not.

Only the children born to mothers of the Luo ethnic group have significantly higher mortality risks than those born to Kikuyus. The interaction of ethnicity and migration status was tested and it was found (results not shown) that the higher mortality among Luos is independent of the mother's duration of residence and of the child's place of birth. As expected from other findings, children born of non-educated mothers have higher mortality $(\mathrm{HR}=1.6 ; p<0.10)$. The effect of mother's death is very strong $(\mathrm{HR}=$ 9.8) but not significant due to small number of years at risk. Children whose mother died have a much higher chance to out-migrate so that they form a very small proportion $(0.22 \%)$ of the population at risk in the slums. Most measures of socioeconomic status had no significant effect on child mortality except for dwelling ownership, which significantly reduces the risk of mortality $(\mathrm{HR}=0.5, p<0.01)$ and ownership of a television, which marginally decreases the risk of mortality for children $(\mathrm{HR}=0.8 ; p<0.05)$. There is no significant reduction of mortality over the period.

\section{DISCUSSION}

Many studies have assessed the risk of infant and childhood mortality and associated risk factors. ${ }^{20-22}$ However, these studies are mostly based on crosssectional data, known to be less appropriate for the analysis of most vital demographic events. The few studies that use longitudinal techniques are based on rural settings ${ }^{23}$ and the risk factors assessed rarely include migration.

The key studies that have specifically examined the effect of migration on child survival ${ }^{3,24-26}$ have also been based on cross-sectional data, with limited migration data. In the present study, we used longitudinal data collected from poor urban slum settlements in Nairobi City, Kenya, to assess the effect of the mother's duration of residence and child's place of birth on childhood mortality. This study contributes to the understanding of the underlying factors for the relatively high disease burden exhibited by slum residents. $5,9,11$ 
Our regression results controlling for attrition and other factors show that children born before their mother's migration have a survival advantage on those who were born after. Children born in slum settlements shortly after their mothers migrated have 1.8 times higher risk of dying than other children. The combination of the migration of the mother while pregnant and of the delivery in the slums appears particularly deadly. Non-slum-born children of recent migrant mothers (i.e., those who gave birth within 19 months after their migration) do generally better than slum-born children. Children born to longer term resident mothers do not show significant difference by place of birth. For recent migrant mothers, delivering out of the slums may have a protective effect on the children. For newborns, living their first few weeks in slums is a serious health hazard, and is certainly considered as such by their mothers. The delivery outside the slums may indicate a positive effect of socioeconomic network on child survival.

The out-migration propensity effect on reducing mortality also shows that outmigration is selective of people who are more prone to poorer health outcomes, and that the mortality rates in slum settlements would actually be higher than the observed rates if many of the people who are leaving the locations stayed there longer. Slum-born children of recent migrant mothers are more often out-migrating than other children. It would be worth collecting morbidity data to investigate whether their out-migration reflects their bad health.

Out-migration is lower for households with better economic indicators as measured by ownership of household assets (including ownership of dwelling units). On the contrary, according to another study using the same data, new in-migrants are less likely to be employed and make less money. ${ }^{27}$ This calls for the need to understand why the mother being new in the slum setting, other factors being equal, exposes children to higher risks of dying. The observed outcome may partly reflect lack of appropriate measurements of economic status and access to health care in the present study. However, evidence from other countries ${ }^{25,26}$ points to the adaptation problems that new migrants often face when they come to new settings. The new migrant mothers may not yet be integrated into the new environment and may not know how and where to seek health care services for their children. Further investigation would be needed to check whether many children born in the slums of recent migrant mothers are unwanted children whose mother is not prepared to care for. Kiros and White ${ }^{28}$ reported in Ethiopia low vaccination coverage (vaccination was provided free of charge) among children from migrant mothers compared with those from non-migrants and explained these differences by the integration level of the mother in the host community. The apparent protective role of delivering out of the slum might actually be an indication that the recent migrant mother's connection to her origin community is playing positively on her child's survival against the health hazards encountered in a slum environment.

We also identified other major risk factors associated with childhood mortality in the slums. The significant effect of ethnicity on mortality suggests cultural effect on child mortality. ${ }^{29}$ Children born to Luo mothers have significantly higher risks of dying than other children, irrespective of the migration status. While our findings call for more detailed case studies of the ethnic effect, they converge with other surveys like the KDHS that show that Luos exhibit poorer health outcomes, including child mortality, than other ethnic groups in Kenya. Ethnic group differences in mortality risk have also been reported in other settings. ${ }^{23,29}$ However, it should be noted that most Luos come from Nyanza province, a region which is particularly affected by HIV/TB, so that the cultural effect on child mortality might be quite indirect, acting through the influence of cultural practices on HIV/TB transmission. According to a 
2007 national survey on HIV prevalence in Kenya, the national prevalence rate among adults aged $15-64$ years was $7.1 \%$ with wide regional variation in adult HIV prevalence, ranging from $14.9 \%$ in Nyanza to $0.8 \%$ in North Eastern province (KAIS-2009). Although the prevalence rates are not available for children, it is probable that Nyanza Province also has the highest prevalence for children.

Most socioeconomic factors were not significantly associated with mortality risk. The exception is dwelling ownership. More than $90 \%$ of the children lived in rented housing where their mothers would not invest so much in improving the living conditions by anticipation of the next migration or by fear of losing their investment to the owner. The minority of mothers whose households own their dwelling units may have longer prospects and may chose to improve their environment and that of their children to the effect of reducing health hazards.

Another major risk factor for childhood mortality is the death of the mother, which multiplied the risk of mortality by 9.8 , albeit not significantly. Similar findings have been seen in other studies. ${ }^{23,30}$ Children who lose their mothers are likely to be exposed to several factors that can increase their mortality risk, including: reduction of care, cessation of breastfeeding, improper bottle feeding, and HIV transmission from their mothers. Due to the HIV/AIDS epidemic, an increasing number of children are experiencing the death of their mother and so the impact on childhood mortality will be substantial. The death of the mother increased very significantly the risk of out-migrating by 2.9. Unfortunately, data did not allow us to know where these orphans go, to their mother's place of origin, to another household in the city or to an orphanage.

Finally, our data generated from the NUHDSS were appropriate to explore and assess risk factors associated with childhood mortality. However, classic determinants of child mortality such as birth interval and birth order were not available for all children and therefore could not be included in the model. Another major limitation is that most of the variables included in our model were not timedependent, except for trimester that captures the trend over the study period, death of the mother, and notice of demolition used as an instrumental variable in the outmigration model. For instance, we only used the household economic status data that were collected close to the date of birth or in-migration of the child, and these could have changed over the study period. The NUHDSS collected household amenities data for all in-migrating households as well as those recruited through the initial census. The project started collecting data on household amenities and assets annually from 2006. This will allow treatment of these proxy measures of household economic wellbeing as time-varying variables in future analyses.

\section{CONCLUSION}

Childhood mortality in these two Nairobi informal settlements remains very high, especially among children born in the slums to new migrant mothers. While emerging evidence highlights the need to pay attention to the plight of slum dwellers in African cities, this study demonstrates the need to look at inequities in health outcomes even within the so-called "marginalized groups." Given the high degree of circular migration, in the context of persisting large socioeconomic inequities between sending and receiving areas, it is important for designing targeted health policies to pursue analysis of the factors predisposing children of recent migrants to such high risks of mortality in the slums. 


\section{ACKNOWLEDGEMENTS}

We would like to acknowledge the contribution of APHRC's dedicated NUHDSS fieldworkers, team leaders, field supervisors, and the Field Coordinator for their efforts in collecting the NUHDSS data in the field. We are also grateful to the data entry and management team for processing the data and making it available for the analysis. Especially, we would like to thank Zewdu Woubalem, Jacques Emina, and Patricia Elungata for the remarkable preliminary data cleaning and processing work. We are also profoundly grateful to the residents of Korogocho and Viwandani slum settlements for taking their valuable time to respond to our questions when our fieldworkers visit their households every four months. Analysis and writing time is supported by funding from the Wellcome Trust (Grant Number GR 07830M), the William and Flora Hewlett Foundation (Grant Number 2006-8376) and the Rockefeller Foundation (Grant Number 2008 AR 001). The NUHDSS is member of the INDEPTH Network.

\section{REFERENCES}

1. UN-HABITAT. The Challenge of Slums: Global Report on Human Settlements. 2003.

2. Gould WT. African mortality and the new "urban penalty". Health Place. 1998;4 (2):171-181.

3. Bocquier P, Madise N, Zulu E. The impact of urbanization and migration on child mortality in sub-Saharan Africa. Demography. 2010 (in press).

4. Van de Poel E, O'Donnell O, Van Doorslaer E. Are urban children really healthier? Evidence from 47 developing countries. Soc Sci Med. 2007;65(10):1986-2003.

5. African Population and Health Research Center. Population and health dynamics in Nairobi's informal settlements: report of the Nairobi Cross-sectional Slums Survey (NCSS) 2000. Nairobi: African Population and Health Research Center; 2002.

6. Dodoo FN, Zulu EM, Ezeh AC. Urban-rural differences in the socioeconomic deprivation-sexual behavior link in Kenya. Soc Sci Med. 2007;64(5):1019-1031.

7. Magadi MA, Zulu EM, Brockerhoff M. The inequality of maternal health care in urban sub-Saharan Africa in the 1990s. Popul Stud (Camb). 2003;57(3):347-366.

8. Mugisha F, Zulu EM. The influence of alcohol, drugs and substance abuse on sexual relationships and perception of risk to HIV infection among adolescents in the informal settlements of Nairobi. J Youth Stud. 2004;7(3):279-293.

9. Ndugwa RP, Zulu EM. Child morbidity and care-seeking in Nairobi slum settlements: the role of environmental and socio-economic factors. J Child Health Care. 2008;12(4):314-328.

10. Zulu EM, Dodoo FN, Ezeh AC. Sexual risk-taking in the slums of Nairobi, Kenya, 19931998. Popul Stud (Camb). 2002;56(3):311-323.

11. Kyobutungi C, Ziraba A, Ezeh AC, Yé Y. The burden of disease profile of residents of Nairobi's slums: results from a demographic surveillance system. Pop Health Metrics. 2008;6:1.

12. National Council for Population and Development (NCPD) [Kenya], Central Bureau of Statistics (CBS) [Kenya], Macro International Inc. Kenya Demographic and Health Survey 1998. Calverton, Maryland; 1999.

13. Bocquier P, Agwanda AO, Khasakhala A, Nyandega I, Owuor S, editors. Biography of three generations of Nairobi residents-thirty years of social urban history. Dakar: Codesria; 2009.

14. Zulu E, Beguy D, Mudege N, Muindi K, Batten L. Characteristics of recent in-migrants in the Nairobi urban health demographic surveillance system. Paper presented at: Population Association of America Annual Meeting [Session 170: The Structuring of Internal Migration]. April 30-May 2, 2009. Detroit, MI. 2009.

15. Konseiga A, Zulu EM, Bocquier P, Muindi K, Beguy D, Yé Y. Assessing the effect of mother's migration on childhood mortality in the informal settlements of Nairobi. In: 
Collinson MA, Adazu K, White MJ, Findley SE, eds. The dynamics of migration, health and livelihoods: INDEPTH network perspectives. Aldershot: Ashgate; 2009; pp. 123-138.

16. Beguy D, Bocquier P, Zulu E. Circular migration patterns and determinants in Nairobi slum settlements. Demographic Research. 2009; 23(20):549-586.

17. African Population and Health Research Center. Addressing Attrition and Follow-up of the NUHDSS Population. Nairobi: APHRC (Data Unit Team); 2008.

18. Clark S, Collinson M, Kahn K, Drullinger K, Tollman S. Returning home to die: circular labour migration and mortality in South Africa. Scand J Public Health Suppl. 2007;69:35-44.

19. Collinson MA, Adazu K, White M, Findley SE, eds. The dynamics of migration, health and livelihoods: INDEPTH network perspectives. Aldershot: Ashgate; 2009.

20. Gyimah SO. Ethnicity and infant mortality in sub-Saharan Africa: the case of Ghana. Discussion paper. London, Canada: University of Western Ontario: Population Studies Centre; 2002.

21. Mboup G. Mortality of children under five years of age [Mortalité des enfants de moins de cinq ans]. In: Institut National de la Statistique et de l'Analyse Économique [Benin], ORC Macro, eds. Enquête Démographique et de Santé au Bénin 2001. Calverton, Maryland (USA): INSAE and ORC Macro; 2001:115-124.

22. Ouoba P. Mortality of children under five years of age. [Mortalité des enfants de moins de cinq ans]. In: Institut National de la Statistique et de la Démographie [Burkina Faso], Macro International Inc, eds. Enquête Démographique et de Santé, Burkina Faso 199899. Calverton, Maryland (USA): INSD and Macro International Inc.; 2000:135-144.

23. Becher H, Müller O, Jahn A, Gbangou A, Kynast-Wolf G, Kouyaté B. Risk factors of infant and child mortality in rural Burkina Faso. Bull World Health Organ. 2004;82 (4):265-273.

24. Brockerhoff M. Rural-to-urban migration and child survival in Senegal. Demography. 1990;27(4):601-616.

25. Brockerhoff M. Child survival in big cities: the disadvantages of migrants. Soc Sci Med. 1995;40(10):1371-1383.

26. Stephenson R, Matthews Z, McDonald JW. The impact of rural-urban migration on under-two mortality in India. J Biosoc Sci. 2003;35(1):15-31.

27. Zulu E, Konseiga A, Muindi K, Darteh E, Mberu B. Migration and the urbanization of poverty in sub-Saharan Africa: the case of Nairobi City, Kenya. Paper presented at: 2006 PAA Annual Meeting Los Angeles, March 30-April 1, 2006; Los Angeles, CA.

28. Kiros GE, White MJ. Migration, community context, and child immunization in Ethiopia. Soc Sci Med. 2004;59(12):2603-2616.

29. Blacker JGC. Infant and child mortality: development, environment, and custom. In: Feachem RG, Jameson DT, eds. Disease and mortality in sub-Saharan Africa. Oxford: Oxford University Press; 1991; pp. 75-86.

30. Koblinsky MA, Tinker A, Daly P. Programming for safe motherhood: a guide to action. Health Policy Plan. 1994;9(3):252-266. 